\title{
STATUS REPORT ON THE OAK RIDGE 25 MV TANDEM ACCELERATOR*
}

N. F. Ziegler, E. G. Richardson, J. E. Mann, R. C. Juras, C. M. Jones, J. A. Biggerstaff, and J. A. Benjamin Oak Ridge National Laboratory Oak Ridge, TN 37830

\section{Introduction}

A new heavy-ion accelerator facility $[1,2]$ is nearing completion at the Oak Ridge National Laboratory. This paper presents a brief description of the scope and status of this project and a discussion of some aspects of the first operational experience with the $25 \mathrm{MV}$ tandem accelerator which is being provided by the National Electrostatics Corporation (NEC) as a major component of the first phase of the facility.

\section{Project Scope and Schedule}

Construction of this facility will proceed in at least two phases. Phase I, which is now under way, consists of a new 25 MV tandem accelerator, improvements to and modifications of the existing oak Ridge Isochronous Cyclotron (ORIC) [3], and a building addition to house the tandem accelerator. After completion of Phase I, it will be possible to operate the two accelerators independently and also in a coupled mode $[4,5,6]$ in which beams from the tandem accelerator are injected into the ORIC for further acceleration. In Phase II [7], it is proposed to modify the ORIC by addition of superconducting main field coils to increase its $K$ value $\left(K=M E / q^{2}\right)$ from the present value of 100 to a value of about 300 .

Since the tandem accelerator has been described previously $[1,2,8,9,10]$, only highlights will be noted here. The accelerator, which is insulated with pure $\mathrm{SF}_{6}$ at pressures up to about $0.7 \mathrm{MPa}$ (gauge), has been designed to operate at terminal potentials of up to 25 MV with analyzed beam intensities up to 1 puA $(0.62 \times$ $\left.10^{13} \mathrm{particles} / \mathrm{sec}\right)$. The accelerator pressure vessel, which is approximately $30 \mathrm{~m}$ high and $10 \mathrm{~m}$ in diameter, houses a column structure $18.9 \mathrm{~m}$ long (excluding the high voltage terminal) of which $16.5 \mathrm{~m}$ is insulated. As shown in Figure 1, the accelerator has a vertical, folded configuration. The column structure is equipped with five dead sections with vacuum pumps and electron traps in each dead section. In addition to the terminal magnet, which provides excellent charge state separation, the column structure is equipped with three quadrupole lenses, three sets of steerers, and a "second" stripper located in the upper major dead section. The accelerator uses a CAMAC-based digital control system in which virtually all control and monitoring information is transmitted on five bitserial highways. A photograph of the column structure is shown in Figure 2 .

A brief chronology of schedule milestones relevant to the tandem accelerator is shown in Table 1. As can be seen, work started on the accelerator system in May 1975 and beam was successfully transmitted through the entire system in May 1980. The remainder of the paper

* Research sponsored by the Division of Basic Enercy Sciences, U.S. Department of Energy, under contract W-7405-eng-26 with the Union Carbide Corporation.

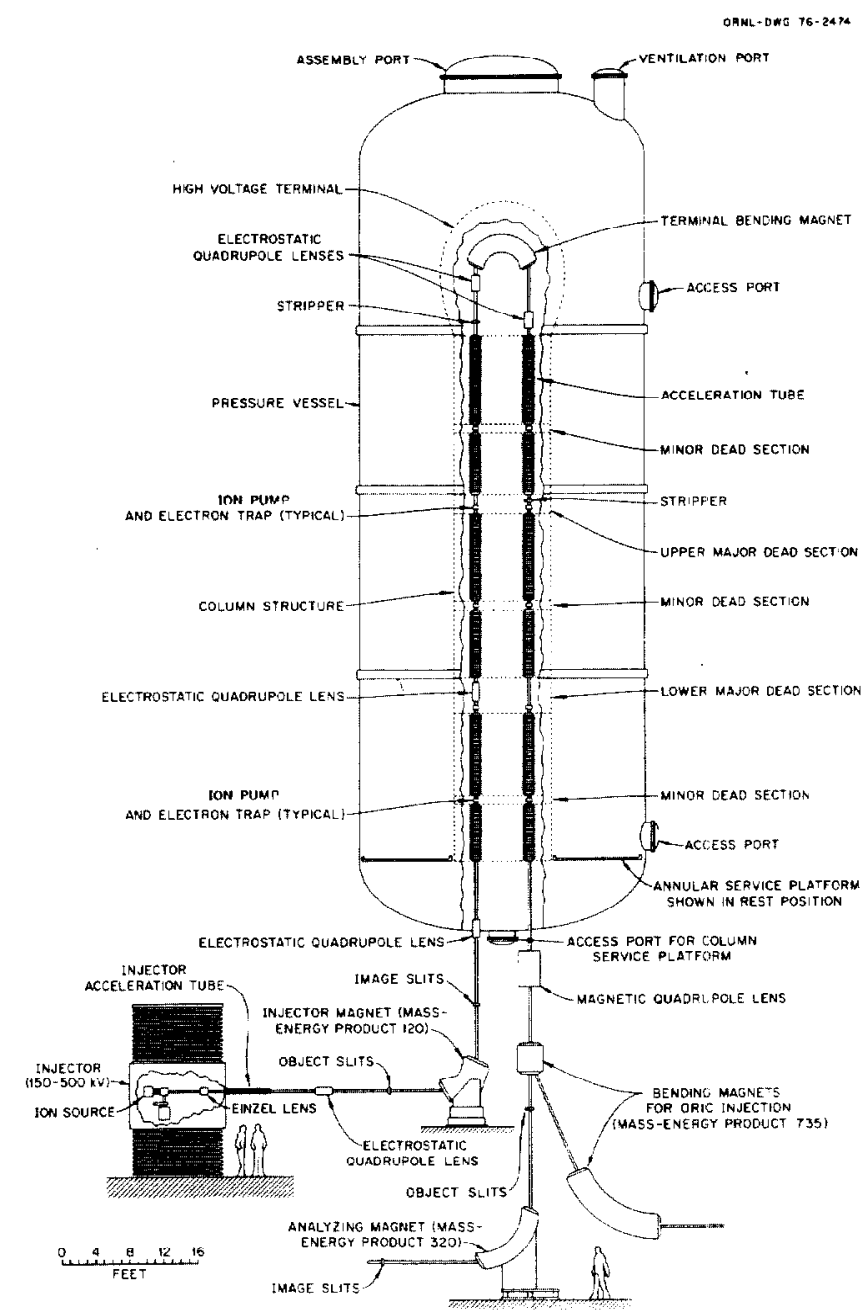

Fig. 1. A simplified schematic drawing of the Oak Ridge 25 MV tandem accelerator.

will be devoted to brief discussions of the $S_{6}$ handling system, column voltage tests, initial operation with beam, and the current status of the accelerator.

\section{$\mathrm{SF}_{6}$ Handling System}

Essentially conventional $\mathrm{SF}_{6}$ transfer, storage, and recirculation systems have been provided for the accelerator. The SF, inventory is stored in the liquid phase in three vessels. 0il-free reciprocating compressors, Kinney vacuum pumps, and a steam-heated vaporizer are used to transfer $S F_{6}$ to and from the storage and accelerator vessels. The system is controlled from a central point by a hard-wired control system which utilizes components typically used in chemical process systems. 
Table 1. Heavy Ion Facility Milestones

November 1974

May 1975

Apri 11976

January 1978

September 1978

October 1978

December 1978

April 1979

Apri1 1979

May 1979

February 1980

May 1980

July, August 1980

January 1981
Project authorized by Congress

Contract signed with NEC

Building construction started

Installation and testing of pressure vessel complete

Injector and column structure tested in air under computer control (in Madison)

$\mathrm{SF}_{6}$ shipment complete $-128,000 \mathrm{~kg}$ on hand

Building completed

Column installation completed (with chains and shafts)

$S_{6}$ transfer system commissioned

column voltage tests (without acceleration tubes)

Column complete (with acceleration tubes) - ready for beam tests

First successful transmission of beam through entire system (0xygen $6+$ at $15.5 \mathrm{MV}$ )

Acceptance tests at $7.5 \mathrm{MV}$ and 17.5 MV successfully performed

First successful coupled operation of tandem accelerator and ORIC (Extracted beam of $401 \mathrm{MeV} 160^{8}$ )

The transfer system was commissioned in April 1979 and used for the first time to pressurize the accelerator vessel to full pressure in May 1979. Since that time, 22 complete transfers (storage to accelerator to storage) have been accomplished without major incident or $\mathrm{SF}_{6}$ loss. The present estimated transfer times under optimum conditions are storage to accelerator (0.55 $\mathrm{MPa}$ (gauge)): $131 / 4$ hours and accelerator $(0.55 \mathrm{MPa}$ (gauge)) to storage: $11 \mathrm{~T} / 4$ hours.

\section{Column Voltage Tests}

Tests of the voltage holding capability of the column structure before installation of acceleration tubes were performed by NEC in May 1979. In these tests, which have been described in detail in Reference 10 , the accelerator was filled with $\mathrm{SF}_{6}$ to a set of test pressures ranging between $0.034 \mathrm{MPa}$ (gauge) and $0.62 \mathrm{MPa}$ (gauge). At each test pressure, a set of measurements was made in which the terminal potential was slowly increased until a spark occurred, thus giving a distribution in breakdown voltage for each test pressure. The absolute calibration for the voltage scale of these measurements was established from previous calibrations (in other NEC accelerators) of current vs. gradient in the corona voltage grading system and is estimated to be accurate to $\pm 5 \%$. At the highest pressure, $0.62 \mathrm{MPa}$ (gauge), the breakdown voltage ranged from 26.4 to $32.0 \mathrm{MV}$ with an average value of $28.8 \mathrm{MV}$.

At the two higher pressures, 0.41 and $0.62 \mathrm{MPa}$, there is good evidence for a conditioning phenomena in the sense that breakdown voltage tends to increase with breakdown number. For the highest pressure, for which we have 13 data points, this increase averaces about $1.3 \%$ per breakdown and does not appear to change over the 13 breakdowns. That is, the breakdown voltage does not appear to level off with breakdown number for the number of breakdowns observed. For this reason, we believe that the breakdown voltages observed at 0.62 $\mathrm{MPa}$ represent a conservative measure of the ultimate voltage halding capability of the column structure.

Examination of the column structure after these tests revealed 42 spark hits. The largest of these were characterized by a discoloration of 1 to $2 \mathrm{~cm}$ in diameter with some melting in the center and roughness of the order of $0.25 \mathrm{~mm}$. There was no evidence of any other physical damage to the column structure and no evidence that sparks tended to occur at a previous spark site. Specifically, we see no reason to suppose that the surface roughness associated with a spark hit will pose a functional problem. The distribution of spark hits was approximately uniform over the surface of the high voltage terminal and upper column al though there was some preference for upper terminal surfaces with compound curvature.

\section{Intial Operation with Beam}

In the interval June-December 1979, NEC installed the acceleration tubes, terminal magnet, and other column components such as pumps, lenses, etc., and in January 1980, NEC began the process of commissioning the column in preparation for beam and voltage tests. The interval between January 1980 and May 1980 was characterized by several non-fundamental but timeconsuming problems which delayed the successful transmission of beam completely through the accelerator until May 12, 1980. In this first test, an analyzed beam of $60 \mathrm{pnA}$ of ${ }^{16} \mathrm{O}^{6}$ was accelerated at a terminal potential of $15.5 \mathrm{MV}$. Subsequent milestones for operation with beam are summarized in Table 2 .

The first task to be performed after initial operation of the accelerator with beam was a preliminary calibration of the analyzing magnet over the mass-eneray product range 29 to 110 using ${ }^{16} 0$ beams of various charae states at a terminal potential of 9.2 MV. An absolute calibration was, obtained as part of this series with a $27.4 \mathrm{MeV} 160^{2}$ beam using the

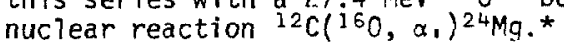

Table 2. Milestones for Operation with Beam

May 1980:

First complete transmission of beam through accelerator system - $1606^{+}$at $15.5 \mathrm{MV}$.

June 1.980:

Absolute calibration of analyzina maanet with the reaction ${ }^{12} \mathrm{C}\left(160, \alpha_{1}\right)^{24 \mathrm{MO} \text {.* }}$

Ju1y 1980:

First system acceptance test

${ }_{127} 10^{+}, 7.5 \mathrm{MV}$, foil stripper, $10 \mathrm{pnA}$ for $10 \mathrm{~min}$.

Aunust 1980:

System acceptance tests

$127 \mathrm{I}^{+}, 7.5 \mathrm{MV}$, gas stripper, $1 \mathrm{puA}$ for $60 \mathrm{~min}, 9.1$ transmission factor.

${ }_{127} \mathrm{I}^{+}, 17.5 \mathrm{MV}$, oas stripper, 1 puA for $60 \mathrm{~min}, 8.9$ transmission factor.

$127 \mathrm{I}^{+}, 17.5 \mathrm{MV}$, foil stripper, $10 \mathrm{pnA}$ for $10 \mathrm{~min}$.

January 1981 :

First successful coupled operation of tandem accelerator and ORIC [6].

injected beam: $\quad 38 \mathrm{MeV} 160^{2}+$

extracted beam: $401 \mathrm{MeV} 160^{8^{+}}$. 
The initial magnet calibration was then followed by performance of the acceptance tests summarized in Table 2. In this table, "transmission factor" is defined as the rat1o of injected beam, as measured at the injector magnet image slits, to the accelerated beam, as measured at the analyzing magnet image slits. These acceptance tests constitute the complete set of system acceptance tests required for terminal potentials of 7.5 and $17 \mathrm{MV}$. During the $7.5 \mathrm{MV}$ gas stripper tests, various charge state $127_{1}$ beams were also used to perform a preliminary calibration of the analyzing magnet over the mass-energy product range 106 to 302 .

A more recent milestone, the first coupled operation of the tandem accelerator and ORIC, is described in detail in Reference 6 . For these tests, the tandem accelerator provided bunched beams of typically 0.4 p $\mu A$ of $160^{2}$ at energies in the range 36 to $40 \mathrm{MeV}$. Typical bunch widths for these initial tests are estimated to be 1 to $1.5 \mathrm{nsec}$.

We have been pleased to note that initial operation of the accelerator with beam, and more specifically, adjustment of the terminal and analyzing magnets in conjunction with the terminal potential has been straightforward. In cases where the terminal gas stripper has been employed, the overall transmission from injector magnet image siits to analyzing magnet image siits, when corrected for the charge state fraction characteristic of the terminal stripping process, typically exceeds $50 \%$. The most significant loss in transmission appears to occur in the low-energy acceleration tube-for reasons which are not yet clear.

\section{Current Status}

In the interval September-October 1980 the accelerator vessel was open for a major maintenance period in which a number of tasks were performed. These included careful baking of the acceleration tubes and replacement of the closed corona voltage grading system with a new open system similar to that used in the Canberra 14UD accelerator [11].

The interval from mid-0ctober to early December 1980 was devoted to inttial conditioning of the acceleration tubes in groups of four and five $61 \mathrm{~cm} \mathrm{sec-}$ tions. (Only minimal conditioning was required for the earlier acceptance tests with beam.) After review of the results of this work, NEC decided to readjust selected acceleration tube spark gaps, a task which was completed in early January 1981 .

The interval from mid-January to the present (mid-March 1981) has been devoted to the ORIC injection tests described above and to further conditioning of the acceleration tubes, again, mostly in groups of four to nine sections. At the present time, all sections have been conditioned to a gradient of at least $0.9 \mathrm{MV} / \mathrm{section}$ and the accelerator has been operated as a whole for brief periods at termina? potentials up to about $22 \mathrm{MV}$. This conditioning period is expected to end in early April, after which a series of beam tests at terminal potentials above 20 MV is planned.

\section{Acknowledgments}

Installation and commissioning of the accelerator has been a cooperative effort involving many ORNL and NEC staff members. It is a pleasure to acknowledge the contribution made by G. M. Klody who has served as the NEC contract manager throughout this period and as NEC's on-site representative for the past year. It is also a pleasure to acknowledge the contributions of the Holifield Heavy Ion Research Facility accelerator operations staff: H. D. Hackler, C. L. Haley, N. L. Jones, S. N. Lane, C. T. LeCroy, C. A. Maples, S. Murray, and C. L. Viar.

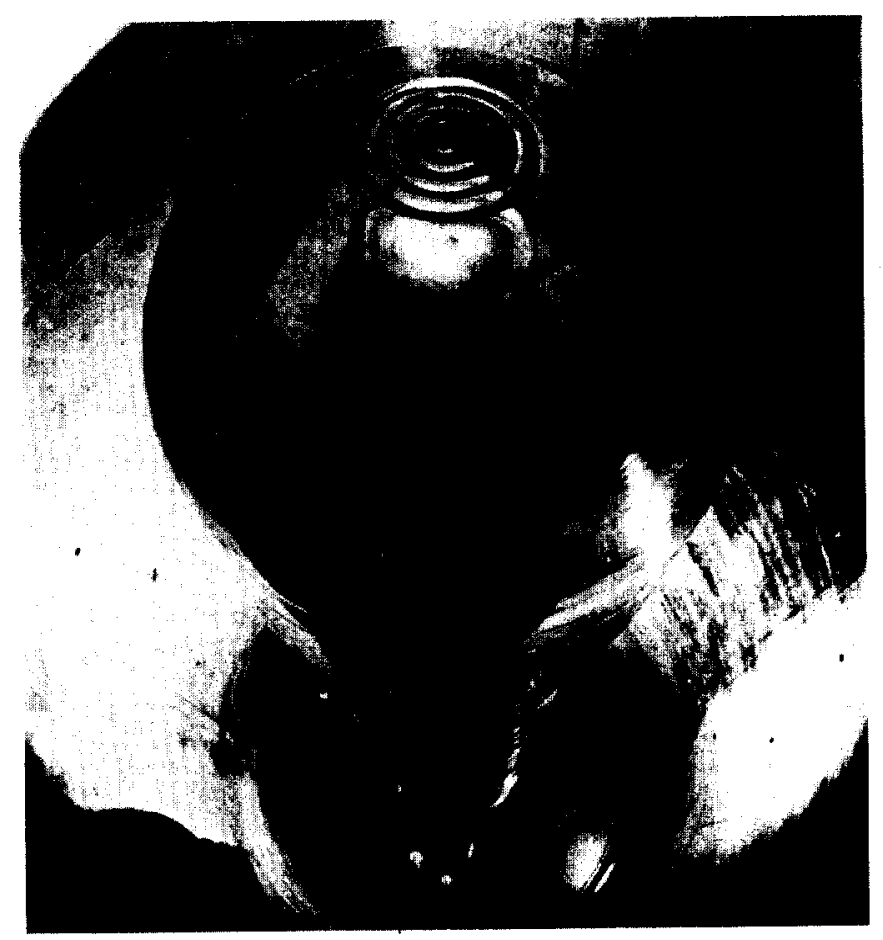

Fig. 2. A view of the completed column structure from above.

\section{References}

1. C. M. Jones, Revue Phys. App1. 12, 1353 (1977).

2. J. A. Martin, IEEE Trans. Nuc1. Sci. NS 26, No. 1, 1439 (1979).

3. R. S. Livingston and F. T. Howard, Nucl. Instrum. Methods 6, 1 (1960).

4. R. S. Lord, J. B. Ba11, E. D. Hudson, M. L. Mallory, J. A. Martin, S. W. Mosko, R. M. Beckers, K. N. Fischer, G. S. McNeiliy, and J. D. Rylander, IEEE Trans. Nucl. Sci. NS 22, No. 3, 1679 (1975).

5. G. S. McNeilly and K. N. Fischer, IEEE Trans. Nucl. Sci. NS 22, No. 3, 1682 (1975).

6. R. S. Lord, E. D. Hudson, J. B. Bal1, R. M. Beckers, C. A. Ludemann, J. A. Martin, S. W. Mosko, and T. P. Cleary, "Coupled Operation of the Oak Ridge Isochronous Cyclotron and the $25 \mathrm{MV}$ Tandem," proceedings of this conference.

7. J. A. Martin, T. P. Cleary, E. D. Hudson, R. S. Lord, P. S. Litherland, G. S. McNeilly, S. W. Schwenterly, and T. A. Weiton, "Study for Superconducting Conversion of ORIC to Increase the Energy from 100 to $300 \mathrm{ME} / \mathrm{q}^{2}$," proceedings of this conference.

8. J. K. Bair, J. A. Biggerstaff, C. M. Jones, J. D. Larson, J. W. McConne 11, W. T. Milner, and N. F. Ziegler, IEEE Trans. Nuc1. Sci. NS 22, No. 3 , 1655 (1975)

9. W. T. Milner, G. D. Alton, D. C. Hensley, C. M. Jones, R. F. King, J. D. Larson, C. D. Moak, and R. 0. Sayer, IEEE Trans. Nucl. Sci. NS 22, No. 3 , 1697 (1975).

10. C. M. Jones, "The 25 MV Tandem Accelerator at Oak Ridge, "Proceedings of the Fifth Tandem Conference, Catania, Italy, June 9-12, 1980, to be published in Nuci. Instrum. Methods.

11. D. C. Weisser, Revue Phys. App1. 12, 1303 (1977). 